Rev.MVZ Córdoba 17(3):3243-3247, 2012.

CASO CLÍNICO

\title{
Plasmocitoma extramedular nasal en un perro
}

\author{
Nasal extramedular plasmacytoma in a dog
}

\author{
Carlos Giraldo M, ${ }^{1}$ M.Sc, Catalina López V,1,2 MVZ, Jorge U Carmona, ${ }^{1 *}$ Ph.D.
}

\begin{abstract}
${ }^{1}$ Universidad de Caldas, Departamento de Salud Animal, Grupo de Investigación Terapia Regenerativa. Manizales, Colombia. ${ }^{2}$ Universidad de Caldas, Programa de Doctorado en Ciencias Biomédicas, Becaria COLCIENCIAS "Generación Bicentenario", Manizales, Colombia. *Correspondencia: carmona@ ucaldas.edu.co
\end{abstract}

Recibido: Noviembre de 2010; Aceptado: Octubre de 2011.

\section{RESUMEN}

Se describe un caso de plasmocitoma nasal en un canino, macho entero, de raza Akita de $30 \mathrm{Kg}$ de peso y veintiún meses de edad, con historia de epistaxis unilateral crónica. Se practicó examen clínico y biopsia de la neoplasia visible en la cavidad nasal izquierda. La ubicación y extensión del tumor fue determinada mediante tomografía computarizada de cabeza y cuello. Se realizaron análisis histopatológico e inmunohistoquímico (IHQ) del tejido tumoral. La tomografía computarizada evidenció una masa con densidad de tejido blando de $10 \mathrm{~cm}$ de longitud $\times 3.5 \mathrm{~cm}$ de diámetro y escasa captación de medio de contraste, que comprometía en su totalidad la cavidad nasal derecha y parte de la porción posterior de la coana izquierda. El análisis histopatológico reveló numerosas células redondas pleomórficas con poco citoplasma, rodeadas por trama escasa de tejido conectivo y bajo índice mitótico. En el examen IHQ la muestra fue negativa a los antígenos CD3 y CD20 para linfocitos T y B, respectivamente. Los hallazgos clínicos y de la tomografía computarizada, así como los resultados del análisis histopatológico del tejido tumoral, fueron compatibles con un plasmocitoma extramedular nasal de bajo grado de malignidad.

Palabras clave: Cavidad nasal, perro, plasmocitoma, tomografía (Fuente: MeSH MEDLINE).

\section{ABSTRACT}

A case of nasal plasmacytoma with history of chronic unilateral epistaxis in a twenty-one month old, male, Akita dog, weighing $30 \mathrm{~kg}$ is described. Clinical examination and biopsy of the visible tumor in the left nasal cavity were performed. The location and extent of the tumor were determined by head and neck computer tomography. Histopathological and immune-histochemical (IHC) analyses of tumoral tissue were performed. Computer tomography showed a mass with soft tissue density of $10 \mathrm{~cm}$ long $\times 3.5 \mathrm{~cm}$ in diameter and low uptake of the contrast medium that entirely compromised the right nasal cavity and part of the rear portion of the left choana. The histopathological analysis revealed the presence of numerous pleomorphic round cells with little cytoplasm, surrounded by a scarce network of connective tissue, and a low mitotic index. The IHC analysis was negative for CD3 and CD20 antigens or T and B lymphocytes, respectively. Clinical and computer tomography findings, such as the results of the histopathology of the tumoral tissue were consistent with a low-grade malignancy extramedular plasmacytoma.

Key words: Dog, nasal cavity, plasmacytoma, tomography (Source: MeSH MEDLINE). 


\section{INTRODUCCIÓN}

Los tumores de la cavidad nasal y de los senos paranasales son de escasa presentación en caninos. Su prevalencia varía del $1-4 \%$ de todos los tumores en esa especie (1) y el $15 \%$ de las enfermedades nasales pueden estar asociadas con neoplasias (2). Las neoplasias nasales afectan principalmente a pacientes mayores de 9 años $(1,2)$. Los tumores nasales se localizan preferentemente en los cornetes etmoidales anteriores, son invasivos localmente y de metástasis infrecuente. Sin embargo, algunos carcinomas en estados tardíos pueden hacer metástasis hacia ganglios linfáticos regionales, pulmones y cerebro (1).

Los perros de razas medianas y gigantes de cráneo dolicocefálico y mesocefálico son los más afectados (1). Se piensa que este tipo de conformación anatómica representa una mayor superficie de contacto para los carcinógenos ambientales (1). Existe una alta proporción de casos en el Airedale Terrier, Basset Hound, antiguo Pastor Inglés, Terrier Escocés, Pastor Alemán, Keeshound y Pointer Alemán de pelo corto $(1,2)$. Se ha establecido una asociación entre humo de tabaco y cáncer canino nasal. Por otra parte, los productos de la combustión de fuentes fósiles parecen estar implicados (1).

Más del $80 \%$ de los tumores nasales en perros son malignos y de estos el $60-70 \%$ son adenocarcinomas y tumores de células escamosas (1). Los tumores nasales de células redondas, tales como linfomas (1, 3-5) y mastocitomas han sido escasamente documentados (1). A este grupo, también pertenecen los plasmocitomas. Sin embargo, de acuerdo con la literatura revisada por los autores, hasta el momento no se ha reportado este tipo de tumor en la cavidad nasal canina.

Los plasmocitomas son neoplasias de células plasmáticas monoclonales de forma redondeada. Estos tumores se clasifican en medulares (si se originan en la médula ósea) y extramedulares (6). Los plasmocitomas extramedulares (PEM) son masas nodulares solitarias de escasa presentación en perros $(6,7)$. Estas neoplasias se localizan con más frecuencia en la piel y membranas mucosas (7).

En este artículo se describe un caso de plasmocitoma extramedular nasal, en un perro de veintiún meses de edad. El paciente fue evaluado con tomografía computarizada (TC), histopatología convencional y análisis inmunohistoquímico (IHQ) del tejido tumoral con anticuerpos para CD3 y CD20.

\section{CASO CLÍNICO}

En el servicio de consulta externa del Hospital Veterinario de los autores, fue presentado un canino, macho entero, de raza Akita de $30 \mathrm{Kg}$ de peso y veintiún meses de edad.

Historia clínica. El paciente presentaba epistaxis unilateral izquierda intermitente $y$ disnea que se agravaba con el ejercicio, con evolución progresiva aproximada de cinco meses. Inicialmente, le fue diagnosticada rinitis alérgica, que fue tratada con antihistamínicos, sin ninguna respuesta. La hemorragia nasal se mantuvo y aumentó gradualmente, por lo que se inició un tratamiento inhalado con beclometasona y clorhidrato de oximetazolina al $0.05 \%$. Después de una semana sin evidencia de mejoría, bajo anestesia general, se practicó examen de las cavidades oral y nasal y se observó una masa vascularizada en la coana izquierda.

Un mes más tarde, se intentó practicar criocirugía de la masa nasal, pero sin éxito. Esto por la localización inaccesible del tumor. Se instauró terapia con prednisolona $(1 \mathrm{mg} / \mathrm{Kg} / \mathrm{PO} / \mathrm{q} 24 \mathrm{~h} /$ durante 7 días), la que podría haber favorecido la aparición de infección nasal purulenta izquierda. Se descontinuó el corticosteroide y se administró amoxacilina $(25 \mathrm{mg} / \mathrm{Kg} / \mathrm{PO} / \mathrm{q} 8 \mathrm{~h} /$ durante 7 días). El tratamiento produjo mejoría transitoria en el cuadro clínico del paciente y disminuyeron los episodios de disnea. Una semana después, la fosa nasal derecha evidenció obstrucción completa y el estado del paciente empeoró, se presentó exacerbación de la epistaxis, respiración estertorosa, incluso mientras dormía. Debido a esa situación se realizó TC y biopsia de la masa nasal.

\section{RESULTADOS}

Hallazgos al examen clínico. El paciente presentó condición corporal normal y sus variables fisiológicas estaban dentro de los rangos normales para la especie. La palpación y auscultación del tórax no reveló presencia de dolor o ruidos respiratorios anormales. Sin embargo, presentó secreción nasal mucupurulenta izquierda, obstrucción completa de la ventana nasal derecha y respiración estertorosa. Aparentemente, los demás sistemas orgánicos estaban normales Por otra parte, los resultados del hemograma y urianálisis fueron normales.

El perro fue anestesiado para practicar una tomografía computarizada (TC) de cabeza y 
cuello y tomar biopsia del tejido tumoral. El medio de contraste empleado fue iopamidol (150 mg dosis total/IV).

Tomografía computarizada. La TC en corte transversal, evidenció una masa con densidad de tejido blando de $10 \mathrm{~cm}$ de longitud $\times 3.5$ $\mathrm{cm}$ de diámetro y escasa captación de medio de contraste. El tumor ocupaba en su totalidad la cavidad nasal derecha y parte posterior de la coana izquierda, sin infiltración de tejidos adyacentes (Figura 1).

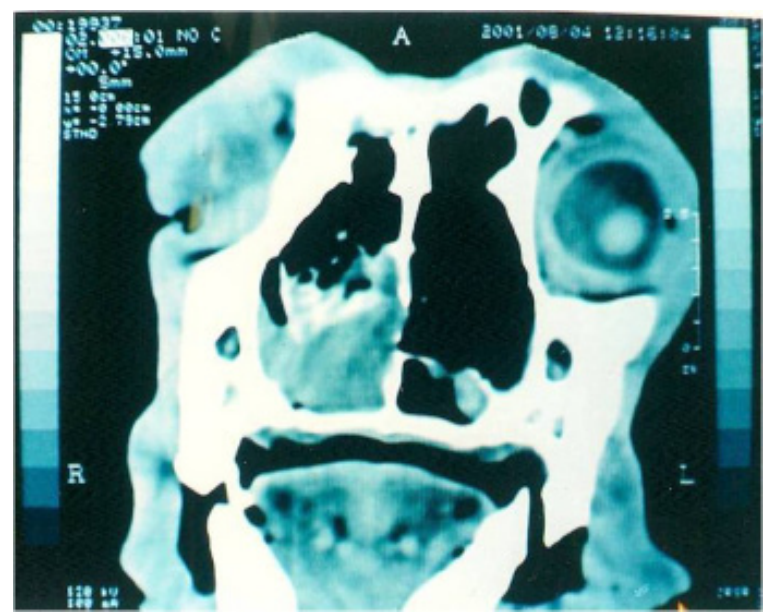

Figura 1. TC de cabeza en corte transversal, tumoración que ocupa la cavidad nasal derecha (R) y parte posterior de la coana izquierda (L), sin infiltración de tejidos adyacentes.

Análisis histopatológico convencional de tejido de la biopsia. Se observaron numerosas células redondas pleomórficas con poco citoplasma, rodeadas por una trama escasa de tejido conectivo y con índice mitótico bajo. Las células tenían apariencia de plasmocitos con escasa cohesión. Estas observaciones fueron compatibles con un tumor de células redondas (Figura 2). Sin embargo, no se pudo diferenciar el tumor entre plasmocitoma y linfoma.

Los resultados de la TC y el análisis histopatológico fueron discutidos con el propietario, quien decidió no continuar con el tratamiento y autorizó la eutanasia del paciente.

Hallazgos de necropsia. El tumor únicamente comprometía la cavidad nasal. Se apreció una masa blanco-amarillenta de consistencia firme y superficie nodular que invadía gran parte de la cavidad nasal e infiltraba ambos cornetes nasoetmoidales. El pasaje nasal derecho estaba obstruido totalmente (Figura 3). No se encontró ningún indicio macroscópico de metástasis.

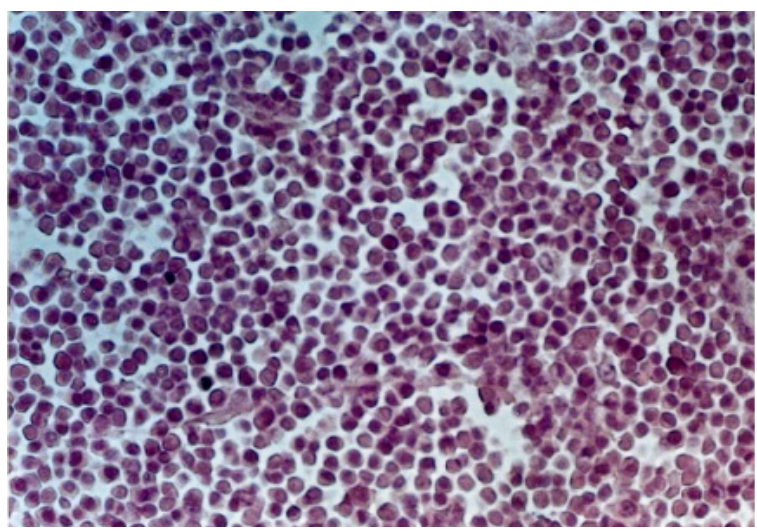

Figura 2. Tejido de biopsia teñido con H\&E, microscópicamente se observa proliferación de células redondas pleomórficas con poco citoplasma, rodeadas de una trama escasa de tejido conectivo y con índice mitótico bajo.

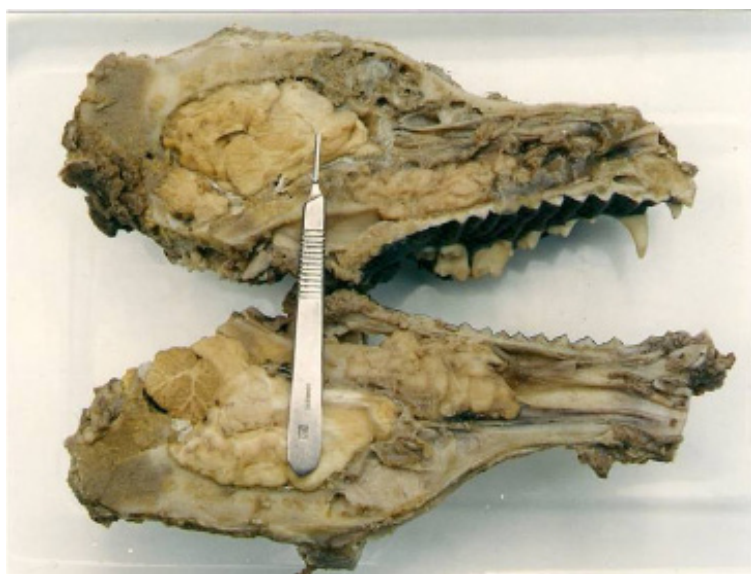

Figura 3. Cráneo con corte longitudinal, macroscópicamente se observa masa blanco-amarillenta de consistencia firme y superficie nodular que invadía gran parte de la cavidad nasal e infiltraba ambos cornetes naso-etmoidales. El pasaje nasal derecho, comparado con el izquierdo, estaba más comprometido y obstruido totalmente.

Inmunohistoquímica (IHQ). Las secciones de parafina del tejido tumoral fueron teñidas con anticuerpos (antihumano) contra los marcadores CD3 $(5,8)$ y CD20 (9), para identificar linfocitos $\mathrm{T}$ y $\mathrm{B}$, respectivamente. Sin embargo, la masa tumoral fue negativa a esos dos antígenos. Por tal razón, el tumor fue clasificado como un plasmocitoma extramedular (PEM) nasal de bajo grado de malignidad.

\section{DISCUSIóN}

Los signos clínicos tempranos asociados con neoplasia nasal pueden incluir estornudo, respiración estertorosa, epifora, descarga 
ocular o nasal unilateral o bilateral crónica (mucopurulenta o sanguinolenta que no responde a antibióticos) y epistaxis $(1,2)$. En estados tardíos o demasiado insidiosos, se ha descrito edema facial o deformidad de huesos nasales y exoftalmia (1). Además, se han reportado signos neurológicos asociados con cambios de comportamiento y convulsiones (1). Las alteraciones paraneoplásicas son frecuentes y pueden incluir anemia e hipercalcemia, entre otras (1). Los signos evidenciados por el paciente de este reporte, coincidieron con la sintomatología asociada con neoplasia nasal temprana $(1,2)$.

Según el conocimiento de los autores, este es el primer caso de PEM diagnosticado en la cavidad nasal de un canino, aunque se han reportado casos que afectan la piel, hígado, intestino, laringe, tráquea y cerebro en esta especie (7). Un hecho llamativo de este reporte, fue la aparición temprana de la neoplasia (21 meses de edad) en comparación con los casos de tumores nasales documentados previamente en perros $(1,2)$. No se pudieron establecer los factores que potencialmente desencadenaron el desarrollo de la neoplasia nasal en el paciente de este reporte, ya que este habitaba en un lugar libre de humo de tabaco o de combustibles fósiles (1).

En seres humanos no se han podido establecer las causas que pueden predisponer el desarrollo de PEM, aunque se ha pensado que el estimulo antigénico inflamatorio crónico asociado con colagenopatías autoinmunes o infecciones bacterianas (e.j.: osteomielitis y colecistitis, entre otras) puede propiciar la aparición del tumor (10). El hecho de no encontrar ninguna causa aparente asociada con el desarrollo del PEM nasal en el canino de este reporte, hace pensar que en esta especie este tipo de neoplasia tiene un comportamiento epidemiológico diferente y aún desconocido al de los seres humanos.

Se han empleado diferentes pruebas diagnosticas para detectar cambios neoplásicos en la cavidad nasal de los caninos, tales como radiografía, rinoscopia anterograda y biopsia, citología con brocha o por impresión, resonancia magnética nuclear (RMN) y tomografía computarizada (TC). Todos estos métodos difieren en su sensibilidad y especificidad para detectar neoplasia nasal (1). En este caso se utilizó TC y el diagnóstico fue complementado con estudio histológico e IHQ de la biopsia tumoral.
Se realizó TC en el paciente de este reporte, ya que este es un método superior a la radiografía para detectar cambios tumorales en cualquier estructura o área de la cavidad nasal, fácilmente se pueden diferenciar de procesos infecciosos y constituye la mejor técnica no invasiva para planear el tratamiento (radioterapia y cirugía) (1). La TC del paciente de este estudio permitió valorar el tamaño y la extensión de la neoplasia y lo observado coincidió con los hallazgos de necropsia (Figuras 1 y 3 ).

El diagnostico preliminar de tumor de células redondas de la neoplasia nasal evaluada, se logró mediante la coloración clásica del tejido de la biopsia con hematoxilina-eosina (H\&E) (Figura 2). La clasificación final del tumor se efectuó por descarte, ya que el examen IHQ de la muestra fue negativo para los anticuerpos (antihumano) contra los marcadores CD3 y CD20 $(8,11)$.

Los linfomas caninos presentan inmunoexpresión aberrante de antígenos CD, como CD3 y CD79a, que son los marcadores más utilizados para la determinación del linaje celular T y B, respectivamente (8). En el caso de este reporte, se realizó inmunotinción con anticuerpos para CD20, como alternativa a la utilización de anticuerpos CD79a para la identificación de linfoma de células B (9). Un estudio reciente (9) demostró que el gen CD20 canino tiene una alta homología con el mismo gen humano.

La principal limitante de este reporte radica en el hecho de que no se realizó una inmunotinción contra proteínas de cadena ligera lambda (6). Esta prueba IHQ es fundamental para confirmar el diagnostico de PEM en caninos (12). Sin embargo, la evaluación morfológica del tejido de la biopsia con H\&E y la ausencia de marcadores IHQ (CD3 y CD20) específicos para linfoma, hacen pensar que este paciente presentaba un PEM nasal.

El tratamiento de las neoplasias nasales incluye la utilización única o la combinación de radioterapia y cirugía (1). También se utiliza la quimioterapia sola o combinada con radioterapia (1) y la braquiterapia. Se ha demostrado que la radioterapia sola - combinada con cirugía representa el tratamiento más efectivo para los tumores nasales. Sin embargo, la recurrencia local es alta y la metástasis frecuente. Los pacientes sometidos a este procedimiento tienen por lo general un periodo de sobrevida de once 
meses a un año. La cirugía o la criocirugía utilizadas como procedimiento único, no son efectivas para el tratamiento de las neoplasias nasales (1).

En el paciente de este reporte no se realizó ningún tratamiento, porque el propietario eligió su eutanasia por razones de bienestar animal. Los autores coincidieron con este argumento, puesto que la literatura revisada permite concluir que las neoplasias nasales y específicamente el PEM (7), a pesar de ser tratadas agresivamente tienen una supervivencia promedio de 138 días (7).

\section{Agradecimiento}

Los autores agradecen la interpretación de los resultados histopatológicos e inmunohistoquímicos presentados en este trabajo a los profesores Carlos Arturo Sánchez Buitrago, MVZ, MSc y Francisco Javier Pedraza Ordoñez, MV, MSc, de la Universidad de Caldas, Manizales, Colombia, y María del Pilar Pérez Figueroa, MD, Esp, de la Universidad de Antioquia, Medellín, Colombia.

\section{REFERENCIAS}

1. Malinowski C. Canine and Feline Nasal Neoplasia. Clin Tech Small Anim Pract 2006;21(2):89-94.

2. Meler E, Dunn M, Lecuyer M. A retrospective study of canine persistent nasal disease: 80 cases (1998-2003). Can Vet J 2008;49(1):71-6.

3. Ueno $\mathrm{H}$, Isomura $\mathrm{H}$, Tanabe $\mathrm{S}$, Tabuchi H, Yamada K, Sato M. Solitary nonepitheliotropic T-cell lymphoma in a dog. J Vet Med Sci 2004;66(4):437-9.

4. Shankel CA. Choanal lymphosarcoma in a 7-year-old golden retriever: Diagnosis and treatment. Can Vet J 2005;46(2):166-9.

5. Kaldrymidou E, Papaioannou N, Poutahidis T, Karayannopoulou M, Gruys E, Toliou T, et al. Malignant lymphoma in nasal cavity and paranasal sinuses of a dog. J Vet Med Ser A-Physiol Pathol Clin Med 2000;47(8):457-62.

6. Ramos-Vara JA, Miller MA, Pace LW, Linke RP, Common RS, Watson GL. Intestinal multinodular A lambdaamyloid deposition associated with extramedullary plasmacytoma in three dogs: Clinicopathological and immunohistochemical studies. J Comp Pathol 1998;119(3):239-49.

7. Wright ZM, Rogers KS, Mansell J. Survival data for canine oral extramedullary plasmacytomas: A retrospective analysis (1996-2006). J Am Anim Hosp Assoc 2008;44(2):75-81.
8. Sueiro FAR, Alessi AC, Vassallo J. Canine Lymphomas: a Morphological and Immunohistochemical Study of 55 Cases, with Observations on p53 Immunoexpression. J Comp Pathol 2004;131(2-3):207-13.

9. Kano $\mathrm{R}$, Inoiue $\mathrm{C}$, Okano $\mathrm{H}$, Yamazaki J, Takahashi T, Watari T, et al. Canine CD20 gene. Vet Immunol Immunopathol 2005;108(3-4):265-8.

10. Fernández-Pérez $A J$, Sancho-Mestre M, Gras-Albert JR, Talavera-Sánchez J. Plasmocitoma solitario de cabeza y cuello. Presentación de tres casos y revisión de la literatura. Acta Otorrinolaringológica Española 2001;52:715-20.

11. Burnett RC, Vernau W, Modiano JF, Olver CS, Moore PF, Avery AC. Diagnosis of Canine Lymphoid Neoplasia Using Clonal Rearrangements of Antigen Receptor Genes. Vet Pathol 2003;40(1):32-41.

12. Cangul IT, Wijnen M, van Garderen E, van den Ingh T. Clinico-pathological aspects of canine cutaneous and mucocutaneous plasmacytomas. J Vet Med Ser A-Physiol Pathol Clin Med 2002;49(6):307-12. 